\title{
Four-Month-Old Boy With Fever, Hepatosplenomegaly and Diffuse Pulmonary Infiltrations
}

\author{
Fariba Shirvani ${ }^{1, *}$, Zahra Chavoshzadeh $^{1}$, Reza Arjmand $^{1}$, Abdollah Karimi $^{1}$ \\ ${ }^{1}$ Pediatric Infectious Diseases Research Center (PIRC), Mofid Children Hospital, Shahid Beheshti University of Medical sciences, Tehran, IR Iran \\ *Corresponding author: Fariba Shirvani, Pediatric Infectious Diseases Research Center (PIRC), Mofid Children Hospital, Shahid Beheshti University of Medical Sciences, Tehran, IR \\ Iran. Tel.|Fax: +98-2122226941, E-mail: shirvanifariba@rocketmail.com.
}

Received: January 05, 2012; Revised: January 09, 2012; Accepted: February 21, 2012

\begin{abstract}
The (bacille Calmette-Gue' rin) BCG is widely practiced in many countries in pediatric group and is a part of routine vaccination program at birth in IR. IRAN for prophylaxis against tuberculosis, but its efficacy is a matter of debate in different geographic and ethnic regions. Adverse reactions induced by BCG vaccination ranges from BCG adenitis, osteitis, and cold abscess at vaccination site to rare occurrence of disseminated infection (BCG-osis). This Lethal disseminated disease specifically affects children with an immune deficiency and generally develops a few months after vaccination. We report one cases of disseminated BCG infection occurred in a 4 months old boy , with severe combined immunodeficiency and BCG-osis, which resulted from a consanguineous marriage with a history of two sibling death from severe infection. Inoculation of BCG as a live vaccine should be postponed for a few months in suspected neonates of primary immunodeficiency disease, until appropriate screening tests exclude this diagnosis.
\end{abstract}

Keywords: BCG and Salmonella Infection, Disseminated; Child; Severe Combined Immunodeficiency

\section{Introduction}

Bacille Calmette-Guerin (BCG), a live attenuated strain of Mycobacterium bovis vaccine, is routinely given to infants at birth, in endemic regions with tuberculosis (1). Its administration may reduce the incidence of tuberculosis by up to $87.6 \%$ with a wide range of reports (2). This is considered safe in general, but there can be several complications, ranging from regional edema and induration (BCG-itis) to disseminated infection (BCG-osis). The most common complication is abscess formation or suppurative lymphadenitis (3). However, BCG-osis, which is reported with incidence is 0.1 to 4.3 per one million vaccinated children tends to be very serious and has a high mortality rate $(4,5)$. We report a boy with a history of fever and respiratory complaints and hepatosplenomegaly and SCID as immunodeficiency.

\section{Case Presentation}

A 4-month-old boy was admitted with a one-month history of fever and dry cough. He was administered different kinds of oral and intravenous antibiotics, with no improvement. He was the fourth child of consan- guineous parents. The first child of the family was an eight-year-old healthy girl, the second and third children died of severe pulmonary infections in infancy and possible immunodeficiency, though both were fully immunized. His condition and growth parameters were normal based on his mother report. Physical examination proved he had poor growth (height and weight < 3th percentile and head circumference at the 50th percentile) with hepatosplenomegaly (the liver was palpated at $5-6 \mathrm{~cm}$ below the costal margin) and splenomegaly (the spleen was palpated $5-6 \mathrm{~cm}$ below the costal margin) and diffuse pink to purple maculopapular rash on his body which did not resolve until his death. His laboratory tests showed anemia, lymphopenia $<3000 /$ [mm3], normal platelet count, prolonged PT (prothrombin time) and PTT (partial thromboplastin time), high ESR and CRP (C-reactive protein), high LDH and ferritin and progressive increase in cholesterol and triglyceride and low fibrinogen. Bone marrow aspiration did not show any histological figure for malignancy, Hemophagocytosis and complement profile were normal. Flow cytometry and immunoglobulin electrophoresis results are shown in Table 1 and 2 . young ages in children, but BCG has live bacterial component, so newborns with immunodeficiency may experience disseminated BCG infection, which can be lethal. In order to prevent these phenomena, physicians should postpone BCG vaccination at birth in families with history of lethal adverse effects after vaccination at birth.

Copyright (C) 2012, Shahid Beheshti University of Medical Sciencces;. This is an Open Access article distributed under the terms of the Creative Commons Attribution License (http://creativecommons.org/licenses/by/3.0), which permits unrestricted use, distribution, and reproduction in any medium, provided the original work is properly cited. 


\begin{tabular}{lll}
\hline \multicolumn{3}{l}{ Table 1. } \\
\hline & Plow & Cytometry Results of Patient \\
\hline CD3 & 9 & Reference Value\% \\
\hline CD4 & 7 & $59-85$ \\
CD8 & 1 & $30-60$ \\
CD19 & 65 & $11-38$ \\
CD56 & 1 & $6.4-23$ \\
\hline
\end{tabular}

Table 2. Immunoglobulin Electrophoresis of Patient

\begin{tabular}{lll}
\hline & Patient Result & Reference Value \\
\hline IgG & $2.1 \mathrm{~g} / \mathrm{dl}$ & $6.58-18.37 \mathrm{~g} / \mathrm{dl}$ \\
IgA & $<0.3 \mathrm{~g} / \mathrm{dl}$ & $0.7-3.6 \mathrm{~g} / \mathrm{dl}$ \\
IgM & $2 \mathrm{~g} / \mathrm{dl}$ & $0.4-2.67 \mathrm{~g} / \mathrm{dl}$ \\
IgE Elisa & $1 \mathrm{Iu} / \mathrm{ml}$ & Neonate $<1112 \mathrm{mo}<25$ \\
& & $1-10 \mathrm{yr}<144$ adult $<188$
\end{tabular}

Chest X-ray and CT scan are shown in Figure 1 and 2.

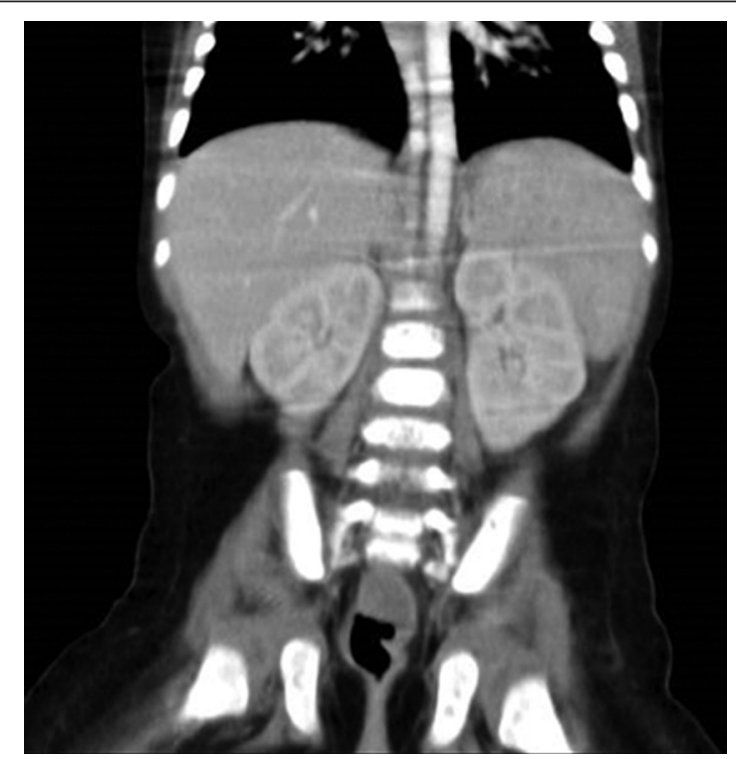

Figure 1. Abdominal CT Scan Shows Hypoechoic Lesions With $2-2.5 \mathrm{Cm}$ Diameter Which Were Observed in Liver as Scattered Micro-Abscesses and Heterogenic Spleen, Kidneys Shows Hypertrophy

Anti-tuberculosis (isoniazide, rifampin, ethambutol, clarithromycin, ciprofloxacin), Pneumocystis carinii (cotrimoxazole), cytomegalovirus (ganciclovir, valacyclovir) and fungal infection (amphotericin B) treatment and supplementary intermittent IVIG and gamma-interferon were started for him, and he became candidate for bone marrow transplantation, but after three months of treatment he died because of disseminated infection. He was diagnosed with disseminated BCG (Bacille CalmetteGuerin) infection (BCG-osis) and SCID (severe combined immunodeficiency). The PCR on the bone marrow speci- men of the patient was positive for Mycobacterium bovis BCG strain (Masih Daneshvari Hospital Mycobacteriology Laboratory). Primary immunodeficiency is an important risk factor for disseminated infection in children who receive live vaccines especially in the first few months of life. Disseminated BCG-osis is the most common infections in SCID, meanwhile other immunodeficiency syndromes such as chronic granulomatous disease (CGD), and IFN-8 receptor 1 or 2 deficiencies, IL-12/ $\beta$ receptor b1 chain deficiency, IL-12p40 deficiency, and STAT1 deficiency can predispose the patients to disseminated BCG infections (5-12). In this patient, T- B+ NK - variant was the responsible immunologic defect.

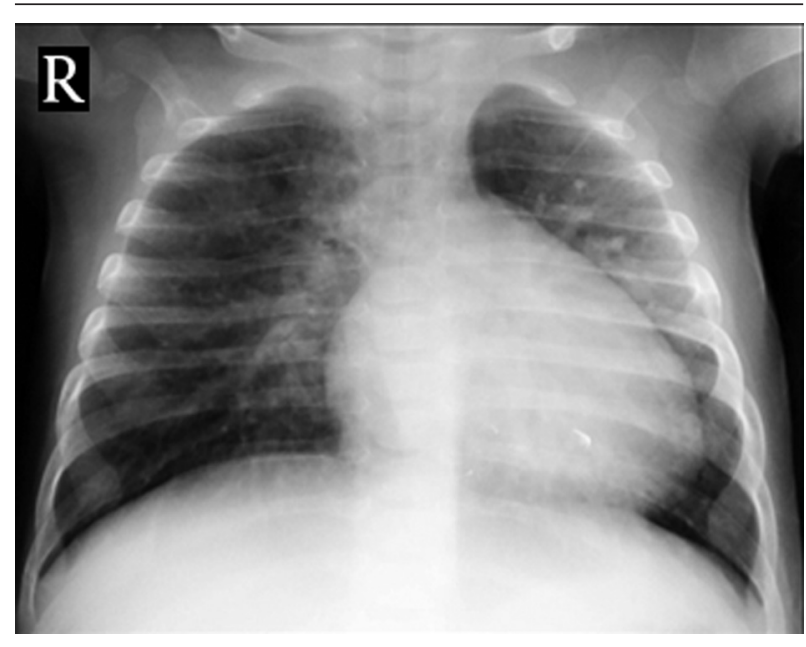

Figure 2. Chest X-Ray Shows Scattered Interstitial Pulmonary Infiltrations

Based on diagnostic guideline for hemophagocytic lymphohistiocytosis (HLH) syndrome, our patient had five out of eight criteria for diagnosis which are fever, splenomegaly, hypertriglyceridemia $(298 \mathrm{mg} / \mathrm{dL} ; \geq 265 \mathrm{mg} / \mathrm{dL}$ is abnormal) and/or hypofibrinogenemia (39mg/ dL, ( $\leq$ $150 \mathrm{mg} / \mathrm{dL}$ is abnormal), low or absent NK cell cytotoxicity ity (as shown by flowcytometry), and finally hyperferritinemia (1244 ng/mL; (> $500 \mathrm{ng} / \mathrm{mL}$ is abnormal). IL-2Rr common chain (X-linked T-B+ NK- SCID), the probable type of immunodeficiency in this patient, is thought to be associated with HLH (13). There are recent reports of coincidence of HLH and disseminated or complicated tuberculosis infection $(14,15)$. This patient seems to have disseminated BCG-osis and T-B+ NK- SCID immunodeficiency and HLH syndrome. BCG vaccination does not prevent tuberculosis infection, but disseminated and meningeal tuberculosis is prevented in 50-80\% of immune competent cases (16). On the other hand, BCG vaccination at birth can have specific effects on T cell function even in normal infants. It was reported for the first time that BCG suppresses $\alpha \beta$ TCR+ T cell counts in healthy infants vaccinated with BCG, but it was not shown that these quantitative changes could lead to functional derange- 
ments in T cells' response However, if it was, this result could be considered important to communities with low income and high malnutrition and/or infectious disease prevalence (17).

\section{Conclusions}

The incidence of new smear positive tuberculosis cases in Iran is approximately high and reaches to 135/100,000 in eastern Iran's neighbor Afghanistan (18). BCG vaccination can be effective in reducing the prevalence of mortality and morbidity from tuberculosis in healthy children, but because of extremely low age of vaccination with a live organism in a human being with complete lack of knowledge of his immunologic status, and very low incidence of disseminated BCG-osis in live births $(1 / 250,000)$ (19), it is wise to recommend postponing the BCG vaccination in families with a history of parental consanguinity and recurrent serious infections or death from infection. Our patient had these two risk factors simultaneously, but in the field of mass vaccination of infants it is hard for health care workers to obtain this information before vaccination. In view of cost effectiveness, policy making strategies in national vaccination programs can consider these important issues. The importance of this case review is demonstration of extreme delay in diagnosis and little attention to family history of death in previous siblings by physicians. Pediatricians are recommended to be aware of possibility of immunodeficiency in infants with positive family history of unusual infections or death, persistent lymphopenia and difficult and/or impossible to treat infections. In suspected neonates of primary immunodeficiency disease, live vaccine is better to be postponed, until appropriate screening tests is developed.

\section{Acknowledgements}

We thank the nurses of pediatric ward and personnel of radiology which help us to get the medical information of our case.

\section{Authors' Contribution}

All authors cooperated equally.

\section{Financial Disclosure}

The authors declare there is no conflict of interests.

\section{Funding/Support}

The study did not receive any fund or support.

\section{References}

1. World Health Organization, BCG vaccine. WHO position paper.
Wkly Epidemiol Rec. 2004;79:27-38

2. Fitoz S, Ikinciogullari A, Dogan BE, Babacan E, Atasoy C, Sahin G Bacillus Calmette-Guerin osteomyelitis in a patient with severe combined immunodeficiency: radiologic appearances of extensive dissemination. Current Problems in Diagnostic Radiology. 2004;33(1):25-7.

3. Sadeghi-Shabestari M, Rezaei N. Disseminated bacille CalmetteGuérin in Iranian children with severe combined immunodeficiency. International Journal of Infectious Diseases. 2009;13(6):e420-e3.

4. Lotte A, Waxz-Hockert O, Poisson N. Complications induced by BCG vaccination: A retrospective study. Bull Int Union Tuberc. 1978;53(114).

5. Rezaei N, Aghamohammadi A, Moin M, Pourpak Z, Movahedi M, Gharagozlou M, et al. Frequency and clinical manifestations of patients with primary immunodeficiency disorders in Iran: up date from the Iranian Primary Immunodeficiency Registry. J Clin Immunol. 2006;26(6):519-32.

6. Huang LH, Shyur SD, Weng JD, Shin C, Huang FY, Tzen CY. Disseminated cutaneous bacille Calmette-Guerin infection identified by polymerase chain reaction in a patient with X-linked severe combined immunodeficiency. Pediatr Dermatol. 2006;23(6):560-3.

7. Yeganeh M, Heidarzade M, Pourpak Z, Parvaneh N, Rezaei N Gharagozlou M, et al. Severe combined immunodeficiency: a cohort of 40 patients. Pediatr Allergy Immunol. 2008;19(4):303-6.

8. Movahedi M, Aghamohammadi A, Rezaei N, Shahnavaz N, Jandaghi AB, Farhoudi A, et al. Chronic granulomatous disease: a clinical survey of 41 patients from the Iranian primary immunodeficiency registry. Int Arch Allergy Immunol. 2004;134(3):253-9.

9. Bustamante J, Aksu G, Vogt G, de Beaucoudrey L, Genel F, Chapgier A, et al. BCG-osis and tuberculosis in a child with chronic granulomatous disease. J Allergy Clin Immunol. 2007;120(1):32-8.

10. Reichenbach J, Rosenzweig S, Doffinger R, Dupuis S, Holland SM, Casanova JL. Mycobacterial diseases in primary immunodeficiencies. Curr Opin Allergy Clin Immunol. 2001;1(6):503-11.

11. Filipe-Santos O, Bustamante J, Chapgier A, Vogt G, de Beaucoudrey L, Feinberg J, et al. Inborn errors of IL-12/23- and IFN-gammamediated immunity: molecular, cellular, and clinical features. Semin Immunol. 2006;18(6):347-61.

12. Moin M, Farhoudi A, Movahedi M, Rezaei N, Pourpak Z, Yeganeh $\mathrm{M}$, et al. The clinical and laboratory survey of Iranian patients with hyper-IgE syndrome. Scand J Infect Dis. 2006;38(10):898-903.

13. Grunebaum E, Zhang J, Dadi H, Roifman CM. Haemophagocytic lymphohistiocytosis in X-linked severe combined immunodeficiency. BrJ Haematol. 2000;108(4):834-7.

14. Joshi R, Phatarpekar A, Currimbhoy Z, Desai M. Haemophagocytic lymphohistiocytosis: a case series from Mumbai. Ann Trop Paediatr. 2011;31(2):135-40.

15. Shivanthan MC, Wijesiriwardena B, Jayaratne B, Gunasekara D, Biyanwila C, Wakawwatta A. Diagnosis of haemophagocytic lymphohistiocytosis in a resource-limited setting. Galle Medical Journal. 2011;16(1):44-6.

16. Kliegman RM, Behrman RE, Nelson WWE, Jenson HB. Nelson Textbook of Pediatrics. Elsevier Science Health Science Division; 2007.

17. Tastan Y, Arvas A, Demir G, Alikasifoglu M, Gur E, Kiray E. Influence of Bacillus Calmette-Guerin vaccination at birth and 2 months old age on the peripheral blood T-cell subpopulations [gamma/delta and alpha-beta T cell]. Pediatr Allergy Immunol. 2005;16(8):624-9.

18. Khazaei HA, Rezaei N, Bagheri GR, Dankoub MA, Shahryari K, Tahai A, et al. Epidemiology of tuberculosis in the Southeastern Iran. Eur J Epidemiol. 2005;20(10):879-83.

19. Stephan JL, Vlekova V, Deist FL, Blanche S, Donadieu J, Saint-Basile GD, et al. Severe combined immunodeficiency: A retrospective single-center study of clinical presentation and outcome in 117 patients. The Journal of pediatrics. 1993;123(4):564-72. 